\title{
Husbandry of tropical benthonic sharks: first step to develop breeding controlled protocols with conservation purpose
}

\begin{abstract}
In the IUCN Red List, Chiloscyllium punctatum, Chiloscyllium griseum and Atelomycterus marmoratusare classified as "Near Threatened" species. ${ }^{1}$ Information's on their biology are strongly lacking and bad human behaviour, associated to irregular fishing practise constitutes sufficient conditions to seriously endanger them in a next future. For all these reasons, species like these could take advantage by research and studies apt to develop protocols for a correct husbandry and for controlled breeding, with the aim to protect global biodiversity. Species above mentioned answer to life in captivity, showing a positive growth rate, consisting in a good correlation in biometric data and so leading to suitable growth models for correct protocols in the future. Next step should consist in controlled breeding.

Keywords: Shark controlled breeding, Husbandry, Chilosclyllium, Atelomycterus marmoratus, Conservation, Protocols, griseum, Benthonic sharks, Chiloscyllium punctatum,Information, Sardina pilchardus, Elasmobranches, Juveniles, Chiloscylliumgriseum, Experimental data, Theoretical relationship
\end{abstract}

Volume 3 Issue 2 - 2015

\author{
Delia Ventura \\ University of Cadiz, Spain
}

Correspondence: Delia Ventura, University of Cadiz, Spain, Tel +39340854480I, Email deli@flabellina.com

Received: October 01, 2015 | Published: November 18, 2015

\section{Introduction}

Chiloscyllium punctatum and griseum are classified in Hemiscyllidaefamily Compagno. ${ }^{2}$ They are small and sluggish benthonic sharks living in coral reefs. C. punctatumis often found in little surface sea pool, where can live until 12 hours, while C.griseum is often present in estuarine waters. ${ }^{3}$ Their typical distributional area is the Indo-Pacific area, until Australia for the first species, where in eastern coasts it's actually protected, while the second species is really common in Indian coasts ${ }^{4}$ Inhabiting the same Indo-Pacific shallows, Atelomycterus marmoratusis also small benthonic shark, classified in Scyliorhinidae family. ${ }^{5}$ it lives in crevices and openings in the reef. They are all menaced by intensive industrial fishing, trawling, coastal pollution and high request for human food market ${ }^{6}$ Up to date information's on their general biology, especially for that concerning reproduction and population structure, are strongly lacking. In addition to that, no monitoring measures have been still adopted by fishing industry in order to ensure suitable management plans for sustainable fisheries. ${ }^{7-9}$ moreover, Aquarium demand for these animals, as ornamental species, is actually growing with obvious devastating effects on coastal ecosystems, caused by inappropriate and illegal fishing practices. ${ }^{10}$

Among the species considered, Atelomycterus marmoratusis the least known.$^{6}$ and by catches and exploitation data are poor. But not for these reasons it should be considered the least threated by the same invasive practices.$^{8}$ Many sharks species, common in public aquaria, are not studied as deserve and most importantly, natural stocks of of conspecifics have been drastically reduced. ${ }^{11}$ For all these considerations, the development of protocols for sharks breeding can be very important for reducing fishing pression on natural stocks and for conservation purposes. ${ }^{10,12}$ Therefore, observation and study of behavioural and physiological adaptations of elasmobranches in public aquaria represent a fascinating, complex and no less valid challenge in scientific research, as well as biodiversity protection, yet to prove the multifaceted roles played by public aquaria.
Since 2009 the Centro Studi Squali of Mondo Marino Aquarium, situed in Massa Marittima (GR, Italy), have been planned research programs for developing controlled shark reproduction protocols in captivity conditions. Tropical and Mediterranean species have been studied also in order to contribute in repopulation processes into the wild, if required in conservation action plans. The specific working program here proposed, aims to get several couples of parents for the species considered in order to formalise the correct husbandry for breeding. The program plans several steps: A) acclimating young sharks, checking feeding and growth rate, B) testing reproduction techniques C) improving eggs development D) stabilising juveniles growth.

\section{Materials and methods}

Between January 2010 and March 2011 some juveniles sharks in three different tanks were acclimatised, fed and monitored: ChiloscylliumgriseumandAtelomycterusmarmoratusin 2.000 litres tanks, Chiloscyllium punctatum, in 250 litres tank. Feeding periodicity, quantity and quality were planned following needs showed by the animals. Diet was most variable as possible and according to their natural habits. All sharks were fed three days per week, while water parameters, except for daily $\mathrm{pH}$, temperature and salinity and biometric data were respectively collected thrice $\left(\mathrm{NO}_{-}, \mathrm{NO}_{-}\right.$, $\mathrm{NH}_{3}, \mathrm{PO}_{-}^{3}{ }_{4}$ ) and once a week. Chemical and physical analyses were performed by using a mercury thermometer, a refractometer (Ruwal RHS-10ATC) and a bench photometer (HI 83203, HANNA), whilst JBL colorimetric test kits were used only for direct $\mathrm{pH}$ measurements. Food quantity was provided proportionally to animal size to avoid surplus, keeping in mind that metabolism in captivity is reduced because of the restricted environment and for the absence for food competition. The species used for a correct feeding satisfy the trophic niche of these species: little bottom fishes, crustaceans and molluscs in lower measure ${ }^{4,13}$

In particular, given fishes were fatty acids 
polynsatured-rich foods, like Scomber scombrus, Sardina pilchardus, Atherinaboyerithe nutritionally rich and complete crustaceans Parapaeneuslongirostrisand finally molluscs Mytilusgalloprovincialis. Foods were frozen to cut down bacteria and intakes were monitored and recorded in terms of weights and species ingested. As usual for elasmobranches in captivity, trace elements supplementation, like potassium iodide, was provided for thyroid health.$^{14}$ Specimens observed were 7 , at juvenile or sub-adult status: two males and one female of Chiloscylliumpunctatum, a pair of Chiloscylliumgriseumand two males of Atelomycterusmarmoratus. Measuring growth as Total Length (L)was made by mean of a smooth woody stick meter to avoid animals get hurt by. Each shark was quickly caught with a soft large-meshed net to minimize stress and traumas and laid down on the meter. For biomass increasing in terms of Body Weight(W), a digital balance with a large flat and useful display was used. Data collected were added into a database.

\section{Results and discussion}

\section{Preliminary observations}

Experimental evidences suggested animals preference for feeding on fishes (Sardina pilchardus, in particular) and pretty slight interest on shrimps (Parapaeneuslongirostris), while bivalves were completely rejected. Sardina pilchardus, as a fatty acids polynsatured-rich food, let this diet trend going well with a number of papers that demonstrated the relatively efficient use of high dietary lipid by both warm water and coldwater fishes.${ }^{15}$ During the entire study period, the animals were constantly fed and in plenty, in spite of their nocturnal habits of predation. Positive trends of growth curves obtained confirmed an increase in biometric parameters (Figure 1).
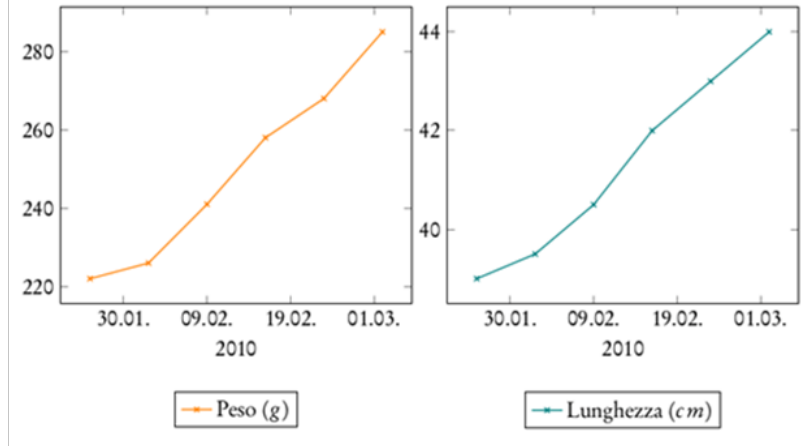

Figure I Chiloscyllium punctatum, Malel. Biometric parameters trend, body weight (Peso, g) and body lenght (Lunghezza, $\mathrm{cm}$ ).

\section{Data analysis}

For a first data analysis, the linear correlation coefficient $\mathbf{r}$ (BravaisPearson) for each data set obtained, body length (L) and body weight (W), has been defined (Table 1). This parameter assumes real values in ${ }^{-1,1}$ and shows a greater or lower linear correspondence for value respectively closer to 1 or 0 . A second analysis approach was the elaboration of regression lines or best fit (Figures 2-4) for each data set, with the aim to show further proportionality between $\mathrm{W}$ and $\mathrm{L}$ and to achieve a theoretical model for comparison with the real growth for each shark observed. Hopefully, the effective growth trend should follow this theoretical model. Best fits ware calculated by using the Le Cren formula.$^{4}$ that just analyses the length-weight correlation:

$$
W=a^{*} L^{b}
$$

$f(x)=1,2378151261 x-261,6302521008$ $f(x)=1,3819742489 x-325,2510729614$
$f(x)=0,9045105566 x-177,6580294306$

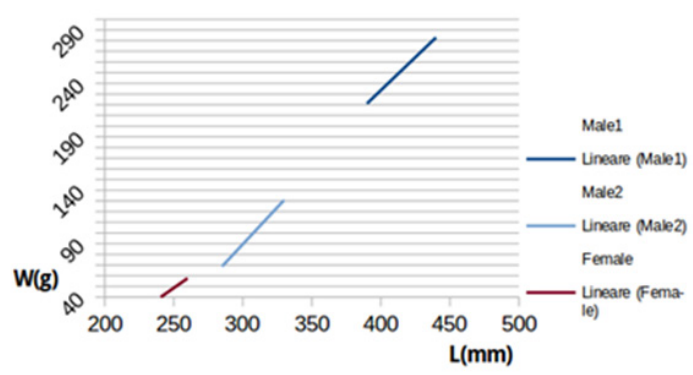

Figure 2 Best Fit for Chiloscyllium punctaum.

$f(x)=2,1180511182 x-590,2468051118$ $f(x)=1,6147299183 x-389,2901136137$

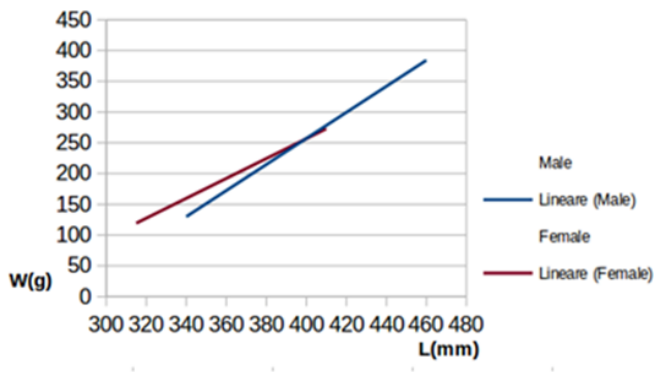

Figure 3 Best Fit for Chiloscyllium griseum.

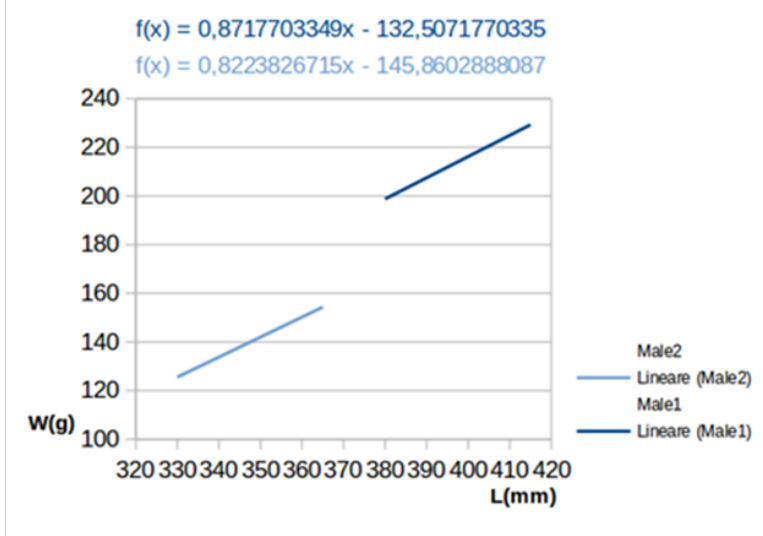

Figure 4 Best Fit for Atelomycterus marmoratus.

Independent variable was fixed in total length because between both biometric parameters considered, it was least likely to be affected by errors. Relative errors were ignored, but absolute error was fixed on a value of 2 (grams), caused by measure instrument (the balance). Test of $\chi^{2}$ was finally calculated to point out how functional relations of best fits obtained actually round up experimental data, according to the formula:

$$
\left.\chi^{2}=\right\rangle_{i=1}^{n}\left(\frac{y_{i}^{\text {teor. }}-y_{i}^{\text {sper. }}}{\sigma_{i}}\right)^{2}
$$


Where, $n$ is the number of experimental points, $\sigma_{\mathrm{i}}$ the accidental error of each measure, $y_{i}^{\text {teor }}$. e $y_{i}^{\text {sper }}$. respectively are the theoretical value expected and the experimental value observed for $\mathrm{Y}(\mathrm{W})$ [16]. A functional relation for a best fit is considered suitable if $\chi^{2}$ takes values approximately equal to $n$. Values of $\chi^{2}$ much higher make the chosen relation unreliable, while if extremely close to $0, \chi^{2}$ suggests nearness among experimental and theoretical values or that experimental errors are overestimated. In the last case not enough information's are available to consider the functional relation fitting with experimental data. Analysis proves that all the sharks fed and grew correctly. In particular, best-fit and $\chi^{2}$ test (Table 2 ) show the best correspondence between experimental data and theoretical relationship for Chiloscyllium punctatum (most clearly in male 1 and female) and good correspondence for Atelomycterus marmoratus. On the contrary, extremely higher values of $\chi^{2}$ for Chiloscyllium griseum specimens make this function unreliable in this study. These analytic results could be effectively corroborated by some behavioural aspects animals showed up, since the Chiloscyllium griseum couple was clearly shyer and quite nervous, even if on the other hand it already reached maturity, showing first sexual intercourses and laying a first egg. Nevertheless, experimental analysis, which is still scarce for the number of specimens considered and data collected, can't be yet considered statistically useful to the point of being generalized as a complete growth model.

Table I Linear correlation coefficient $\mathbf{r}$ for each data set ( $\mathrm{L}$ and $\mathrm{W})$

\begin{tabular}{|c|c|c|c|c|c|c|}
\hline \multicolumn{3}{|c|}{ Chiloscyllium punctatum } & \multicolumn{2}{|c|}{ Chiloscyllium griseum } & \multicolumn{2}{|c|}{ Atelomycterus marmoratus } \\
\hline Male I & Male 2 & Female & Male & Female & Male I & Male 2 \\
\hline 0,998 & 0,99 & 0,968 & 0,994 & 0,989 & 0,97 & 0,958 \\
\hline
\end{tabular}

Table $2 \chi^{2}$ Test and values of $\mathbf{n}$ (see Appendix)

\begin{tabular}{clllllll}
\hline \multicolumn{2}{l}{ Chiloscyllium punctatum } & & \multicolumn{2}{c}{ Chiloscyllium } & griseum & \multicolumn{2}{l}{ Atelomycterus marmoratus } \\
\hline & Male I & Male 2 & Female & Male I & Female & Male I & Male 2 \\
$\chi^{2}$ & 3,791 & 23,884 & 7,120 & 272,898 & 245,326 & 10,254 & 14,093 \\
$\mathbf{n}$ & 6 & 12 & 12 & 15 & 15 & 6 & 6 \\
\hline
\end{tabular}

\section{Conclusion}

Several studies have been realised on various species of elasmobranches and Chiloscyllium griseum . ${ }^{12}$ and Chiloscyllium punctatum. ${ }^{17}$ are among those species that have completed their reproductive cycle in captivity, but not enough data on their biology and behavioural adaptations have been collected. Even if on preliminary stadium, the present study with its considerations, really expresses great potentiality in such researches and would create useful guidelines for future studies, as already observed during the $15^{\text {th }}$ annual scientific conference of the European Elasmobranch Association, held in Berlin in 2011. ${ }^{18}$ This work aims to point out the importance to standardize the entire husbandry process in captivity for threatened species. Collecting data and analysing techniques should be therefore confirmed and optimized, even taking into account different age and gender among individuals. First step of the desirable husbandry protocol here promoted was touched, with acclimatization of young sharks, controlling feeding and growth rate. Nevertheless, to better complete this step and to pass officially to the reproduction phase, for completing a correct husbandry finalised to breeding in specifics protocols, working programs should get several couples of parents for these species (Appendix).

\section{Acknowledgments}

I wish to thank Prof. Primo Micarelli, curator and director of the Aquarium Mondo Marino and his staff of the Centro Studi Squali of Massa Marittima (Gr, Italy), funded by Posidonia" no-profitassociation (Via Sordini 4 P.S. Stefano Monte Argentario, GR, Italy). They provided to me all the technical instruments, informations and support necessary to realise this work.

\section{Conflicts of interest}

None.

\section{References}

1. The IUNC Red list of Threatened Species.
2. Compagno LJV FAO Species Catalogue Vol-4. Sharks of the world. An annotated and illustrated catalogue of shark species known to date. Part 1-Hexanchiformes to Lamniformes. FAO Fish Synop. $1984 ; ; 1 ; 25(4 / 1): 1-249$.

3. Talwar PK, Jhingran AG Inland fishes of India and adjacent countries. Reviews in Fish Biology and Fisheries. 1991;4(1):135-136.

4. Devadoss P Studies on the catshark Chiloscyllium griseum from Indian waters. J Mar Biol Assoc India. 1986;28(1\&2):192-198.

5. Compagno LJV, Niem VH Scyliorhinidae. Catsharks. 1998.

6. Compagno LJV FAO Species Catalogue Vol-4. Sharks of the world. An annotated and illustrated catalogue of shark species known to date. Part 2 - Carcharhiniformes. 1984

7. Bennett MB, Kyne PM Chiloscyllium punctatum. SSG Australia \& Oceania Regional Workshop. 2003

8. White WT Atelomycterus marmoratus. SSG Australia \& Oceania Regional workshop. 2003

9. Lisney TJ, Cavanagh RD Chiloscyllium griseum. SSG Australia \& Oceania Regional workshop. 2003

10. Mackay B, Chua F Aquaculture of tropical marine ornamental fishes at Underwater World Singapore. Bulletin de l'Institut océanographique. 2001;20(1):391-394.

11. Henningsen AD, Smale MJ, Gordon I, et al. Elasmobranch Husbandry Manual: Proceedings of the First International Elasmobranch Husbandry Symposium. 2001

12. Dral AJ Reproduction en aquarium du requin du fond tropical, Chiloscyllium griseum Müll. et Henle (Orectolobidés). Reviews in French Aquariology. 1980;7:99-104.

13. Compagno, LJV Sharks of the world. An annotated and illustrated catalogue of shark species known to date. Volume 2. Bullhead, mackerel and carpet sharks (Heterodontiformes, Lamniformes and Orectolobiformes). 2001;169:138.

14. Smith M, Warmlolts D, Thoney D, et al.x The Elasmobranch Husbandry Manual: Captive Care of Sharks, Rays and their Relatives. Ohio Biological Survey Inc, Columbus Ohio, USA, pp. 2001; 444. 
15. USA Subcommittee on Warmwater Fish Nutrition, Committee on Animal Nutrition, Board on Agriculture, National Research Council Nutrient requirements of warmwater fishes and shellfishes. Revised Edition, National Academy Press Washington, USA, p. 1983;13.

16. Foti A, Gianino C Elementi di analisi dei dati sperimentali. Liguori Editore, Italy, p. 1999;70.

17. Garner R Preliminary report regarding captive breeding observations of the brown-banded bamboo shark, Chiloscyllium punctatum Muller and Henle, 1838. Thylacinus. 1998;22(1):31-32.

18. Micarelli P, Ventura D, Sperone E, et al.Husbandry of tropical benthonic sharks (Chiloscyllium griseum, C. punctatum and Atelomycterus marmoratus): First step to develop protocols for controlled breeding with conservation purpose. Poster in Programme Booklet of The $15^{\text {th }}$ Annual Scientific Conference of the European Elasmobranch Association, Berlin, Germany. 2011. 